\title{
Survivorship and Shame: Tracing the Affective Afterlife of the Holocaust Emily Dutton
}

\begin{abstract}
Many survivors of the Holocaust have carried feelings of shame related to having survived this horrific event. This paper traces a genealogy of shame by exploring the sources of shame that have haunted survivors, and how these have manifested themselves in their lives and the lives of their children. Arguing that the intergenerational transmission of shame has reinforced a culture of silence among survivors and their children, this paper calls for a reconceptualizing of the afterlife of the Holocaust, which leverages shame as a powerful piece of remembering and understanding the Holocaust.
\end{abstract}

Many of those who survived the Holocaust experienced long-lasting physical and psychological trauma from the dehumanizing and torturous environment of concentration camps, and the victimization they encountered under the Nazi regime. However, many survivors also carried haunting feelings of shame and self-hatred for having survived this horrific ordeal. ${ }^{1}$ For some, this shame stems from the unshakeable understanding that they survived when many others did not, while for others this shame is caused by the their actions during the war which they now understand as wrong or corrupt, such as carrying out acts of perpetration towards other prisoners, using sex and prostitution as a survival tool, and acting in selfish and inhumane ways. In this paper I will carry out an exploration of survivor shame, which is rooted in an understanding of shame that draws on the work of affect theorists Sara Ahmed and Jennifer Biddle. I will explore the sources and sites of survivors' shame, and consider how this intense affective sensation has manifested itself in survivors' lives -namely, through a 'cloak of silence' which many survivors have maintained around their experiences during the Holocaust, and the presentation of 'false pride', which works as a mechanism to mask and deny deep-seated shame. By emphasizing how these fallouts of shame have haunted the children and grandchildren of survivors, I will illustrate a shame-centered affective genealogy, which traces the transmission of survivor-shame between first and second-generation survivors. By exploring the intergenerational transmission of survivor shame in Holocaust postmemory, I hope to validate shame as an affectively powerful piece of remembering and understanding the Holocaust.

Shame and its presence in the lives of Holocaust survivors has been investigated by a litany of scholars. And, while contemporary Holocaust literature has focused on an exploration of the presence of 'shame' in the lives of survivors, studies and theories surrounding Holocaust survivorship in the 1960's carried a stronger focus on a theorizing survivor 'guilt'. This move from a discourse of 'guilt' to a discourse of 'shame' is not simply a caveat of language, but an important symbolic shift in how the trauma carried by survivors has been socially and medically understood. Psychoanalysts in the 1960's (such as William Niederland, Henry Krystal and Bettelheim) drew on the work of Sigmund Freud, Sandow Ferenczi and Anna Freud to argue that Holocaust survivors carried feelings of 'guilt' after liberation, which stemmed from their

\footnotetext{
${ }^{1}$ Herny Maitles, "Surviving the Holocaust: The Anger and Guilt of Primo Levi," Journal of Genocide Research 4.2 (2002): 244.
} 
unconscious or imitative identification, or 'mimesis' with Nazi perpetrators. ${ }^{2}$ Their theorizing of survivor guilt revolved around the understanding that "the humiliated prisoner, in the moment of shock, regressively defend[ed] against the persecutor's violence by unconsciously yielding to, or imitatively incorporating, the violent other"3, an understanding which implicated the victim in the violence and suffering imposed upon them. This understanding of survivor guilt was riddled with problems, and many Holocaust scholars and literary critics took issue with its the victimblaming explanation for survivors' emotional trauma. These criticisms prompted a shift within Holocaust discourse, whereby scholars began to move away from the concept of 'guilt' in favor of an ethically 'freer' concept of shame. ${ }^{4}$ This changed conceptualization of survivor's trauma was situated within a larger transition in medical and psychological sciences, literary criticism, and philosophy, where a newly emerging shame theory served as the foundation for various "philosophical, post-psychoanalytic, postmodernists, and political projects and critiques".

Understood by contemporary affect theorists as one of the primary 'negative affects', shame is a complex sensation that is "felt by and on the body" in intense and immobilizing ways. It has an "outer-directed, communicat[ive] and perform[ative]" physiological responses such as burning flesh, blushing and sweating. ${ }^{8}$ Unlike guilt, which is object or action focused, and revolves around the transgression of normative social rules, norms and prohibitions, shame is less activity-centered (in its cause and resolution) and more embedded in one's inadequacy (in the eyes of the self, and the other), it is experienced less related to what the self has done, and more related to what the self is. It is precisely this "identity making"" aspect that renders shame powerful in shaping individuals' sense of self and prompting them to understand themselves as overwhelmingly defined by 'wrongness' or 'badness'. This paralyzing, non-negotiable sense of shame has been noted by Holocaust survivors who admit to being haunted by moral dilemmas they faced during the war, in which they feel they failed to do the 'morally correct' thing, such as, leaving family in order to survive during the war, acting inactive and passively during the war, and acting selfishly without any concern for others. ${ }^{10}$

As we consider shame surrounding Holocaust survivorship, it is necessary to acknowledge the social environment and attitudes that surrounded persecuted individuals in ghettos and concentration camps. In addition, the horrific conditions that prisoners suffered in during the Holocaust created a bubble where normative social rules and behaviors were pushed aside in the name of survival. Concentration camps were defined by norms that transgressed prohibited behaviors in pre-war culture. For instance, some survivors have argued that without selfishness, survivorship was near impossible, and that "even those who attempted at times to retain elements of dignity and humanity could only survive by looking after oneself". ${ }^{11}$ Maitles argued that "in

\footnotetext{
${ }^{2}$ Ruth Leys, From Guilt to Shame: Auschwitz and After (Princeton: Princeton University Press, 2007), 4.

${ }^{3}$ Ibid, 5.

${ }^{4}$ Ibid, 7 .

${ }^{5}$ Ibid, 8.

${ }^{6}$ Sara Ahmed, "Shame Before Others," The Cultural Politics of Emotion, (New York: Routledge, 2004), 103.

7 Jennifer Biddle, "Shame," Australian Feminist Studies 12.16 (1997): 229.

${ }^{8}$ Ibid, 230.

${ }^{9}$ Biddle, "Shame," 230.

${ }^{10}$ Liat Ayalon, "Making Sense Of The Past - Perspectives On Resilience Among Holocaust Survivors," Journal of Loss \& Trauma 104 (2009): 283-286.

${ }^{11}$ Maitles, "Surviving the Holocaust: The Anger and Guilt of Primo Levi," 244.
} 
the camps, compromise with the authorities seemed a natural, even understandable means of attempting to survive". 12

In his testimony-based piece The Drowned and the Saved, Italian Jew Primo Levi, a survivor of Auschwitz concentration camp, spoke of the violation of social norms by prisoners during the war, stating that, "the worst survived - that is, the fittest: the best all died"13, emphasizing that those who survived were "the selfish, the violent, the insensitive, the collaborators of the 'grey zones', [and] the spies". ${ }^{14}$ Indeed, for many, surviving depended on moral compromise and dehumanizing actions and attitudes: stealing bread, not sharing, and considering only one's own needs. ${ }^{15}$ Auschwitz survivor Tadeusz Borowski has similarly depicted survivorship as hinging on disgraceful behavior in his piece This Way for the Gas, Ladies and Gentlemen, where he suggests that there was "persecution and betrayal among prisoners"16 and argues that prisoners "struggled to survive by attaining positions of privilege in the camps -often doing the "dirty work' of destroying Jewish prisoners for the Nazis". ${ }^{17}$ As an Aryan prisoner, Borowski was afforded privilege over Jewish prisoners, privilege which afforded him certain freedoms and opportunities to collaborate and engage with Nazi perpetrators at Auschwitz. He took part in soccer games with the SS crematorium guards, and volunteered to serve on the transport platform where he ushered Jews to their deaths. In this way he was complicit with the Nazi regime and in the killing of other prisoners. ${ }^{18}$ The testimonies offered by Primo Levi and Tadeusz Borowki illustrate the extreme behaviors and moral corruption individuals will embrace in an attempt to save their own lives. However, both Levi and Borowski convey a deep sense of shame and remorse for the human capacity for dehumanizing others and acknowledge their "profound sense of shame [from their] experience[s] in Auschwitz". ${ }^{19}$ Their testimonies illustrate how the haunting memories of perpetration have stuck with some survivors. For Borowski, this shame was all consuming and unmanageable, and feeling that his moral sensibility was destroyed and his humility un-restorable, he ended up taking his own life. ${ }^{20}$

As we consider the burning shame experienced by survivors for their actions during the war, it is important to note that this shame often did not manifest itself intensely until long after liberation. ${ }^{21}$ Arguably, this is because with liberation came the restructuring of what was 'normative' or acceptable behavior in the lives of survivors. The changing social environment brought a shift in how survivors (and those who surrounded them) understood their behavior in concentration camps and ghettos -behaviors that were considered 'legitimate' and necessary for survival during the war became a source of shame outside of these environments. ${ }^{22}$ Reuven, a Holocaust survivor from Slovakia, has recalled the strength of his mother during their time in the Nováky forced labor camp, where she endured sexual violence in order to secure the safety of

\footnotetext{
${ }^{12}$ Maitles, "Surviving the Holocaust: The Anger and Guilt of Primo Levi," 247.

${ }^{13}$ Timothy Pytell, "Shame and Beyond Shame," New German Critique 117 (2012): 162.

${ }^{14}$ Maitles, "Surviving the Holocaust: The Anger and Guilt of Primo Levi," 242.

${ }^{15} \mathrm{Ibid}, 162$.

${ }^{16}$ Ibid, 156 .

${ }^{17}$ Ibid, 156.

${ }^{18}$ Timothy Pytell, "Shame and Beyond Shame," 162.

${ }^{19} \mathrm{Ibid}, 155$.

${ }^{20}$ Ibid, 163 .

${ }^{21}$ Gertrude Schneider, "Survival and Guilt Feelings of Jewish Concentration Camp Victims," 37.1 (2009): 74

${ }^{22}$ Esther Dror, "The Shame is Always There," Sexual Violence Against Jewish Women During the Holocaust (2010): 287.
} 
their family. ${ }^{23}$ At the time, his mother explained to him that this abuse was "was part of life (...) because, otherwise, [they] would have put a bullet through [our] head[s]". ${ }^{24}$ (287). Reuven saw his mother as a "strong woman, with incredible power and resourcefulness". ${ }^{25}$ However, after the war she put up a wall of silence and shame surrounding this experience and faded away "like a candle. She melted down until she was finished (...) [she] went crazy" ${ }^{26}$, overcome by shame, disgrace and trauma rooted in the sexual violence she faced. Reuven's mother's story is evidence of the emotional difficultly of the transition between the world of war where individuals' "willingness to do anything in order to survive one more day is an adaptive quality",27, to a time of relative freedom and comfort with a larger emphasis on "values, culture, and self-respect (preserving human dignity)". ${ }^{28}$ As Reuven's mother made the transition into a free world, she could not adjust, overwhelmed by paralyzing shame.

One of the foundational features of shame is its intensification when it is "seen by others as shame". ${ }^{29}$ The 'shaming' gaze of the other has the capacity to call-out, recognize and expose shame, and works to solidify and reify one's understanding of self as inadequate. As such, "to be witnessed in one's failure is to be ashamed [but] to have one's shame witnessed is even more shaming". ${ }^{30}$ Because shame is magnified through its recognition by others, it triggers a strong impulse to conceal and cover in an attempt to avoid the "exposure, vulnerability and wounding" "31 this affect can elicit. This drive to blanket shame can explain attempts by survivors to mask and deny their trauma through an individually and culturally maintained culture of silence and secrecy. For some survivors, concealing shame means omitting shameful moments and memories from their Holocaust narrative, for others it means maintaining a cloak of silence around their experience of the Holocaust, and in some cases this silence has manifested itself in a denial of that one's family was persecuted, or implicated in the Holocaust. ${ }^{32}$ Indeed, silence can be a means of coping with the trauma and shame of the Holocaust, an attempt to forget shameful memories, and a way of avoiding the retraumatization of re-telling (and re-acknowledging) one's shameful experiences.

While scholarly works and recorded testimony have addressed the shame (and silence) that have stemmed from individuals' own actions during the Holocaust, survivors have also experienced shame for having been persecuted, and carrying a persecuted identity. Scholar Felix De Mendelssohn has recalled this concealed identity-shame in his family, where his mother told him that "[he] should not consider [him]self in any way involved with Jews or Judaism (...) and that no one in the family ha[d] suffered under the Nazis"33 (De Mendelssohn 395). Later in his life, sorting through documents at his parents' home, he discovered his Jewish background and the fact that his mother's “own grandmother had been deported to Terezin (Theresienstadt) and

${ }^{23}$ Dror, "The Shame is Always There," 285.

${ }^{24} \mathrm{Ibid}, 284$.

${ }^{25}$ Ibid, 287.

${ }^{26}$ Ibid, 287.

${ }^{27}$ Ibid,, 287.

${ }^{28} \mathrm{Ibid}, 287$.

${ }^{29}$ Ahmed, "Shame Before Others," 103.

${ }^{30}$ Ibid., 103.

${ }^{31}$ Ibid, 104.

${ }^{32}$ Felix De Mendelssohn, "Transgenerational Transmission of Trauma: Guilt, Shame, And The 'Heroic Dilemma," International Journal Of Group Psychotherapy 58.3 (2009): 393.

${ }^{33}$ De Mendelssohn, "Transgenerational Transmission of Trauma: Guilt, Shame, And The 'Heroic Dilemma" 395. 
killed there". ${ }^{34}$ His mother's fear of being identified as Jewish is shown in her attempts to present herself and her family as integrated Roman Catholic Austrians. Her shame for being personally associated with a Jewish identity revealed itself in her resentment towards the influx of Orthodox Jews from Poland and Galicia who "through their manner of dress and their speaking of Yiddish attracted the anti-Semitism that could ultimately destroy her own tolerated [and concealed] status". ${ }^{35}$ De Mendelssohn acknowledges his own experience of feeling Jewish shame when Israeli athletes were assassinated during the Munich Massacre, arguably an expression of carrying of his mother's concealed Jewish shame. ${ }^{36}$ De Mendelssohn's experience displays the intergenerational transmission of shame from survivors to their children -making it clear that the shame carried by Holocaust survivors is active in the consciences of their children. Indeed, this is why many scholars have referred to the children of Holocaust survivors as 'second-generation survivors', with lives shaped by exposure to indirect and second-hand memory of events that they did not experience.

Many children of survivors have remembered their parents' silence as a mechanism of instilling a private and public sense of taboo around discussing the Holocaust. ${ }^{37}$ Through the unspoken "language of the family" 38 -which Marianne Hirsch describes as "nonverbal and non-cognitive acts of transfer" 39 - that have occurred within family space, children of survivors came to understand the Holocaust and the experiences of their parents during this time as an unbreachable topic which they feared addressing, because of their understanding of the trauma that their parents carried, and a concern that they might trigger shameful memories and reignite that trauma. ${ }^{40}$ Undeniably, this silence has had detrimental effects on children, leading some to cloak their Jewish identity in secrecy. ${ }^{41}$ One second-generation survivor recalls that, "our parents' generation survived by forgetting. Denial was a survival mechanism (...) [they] grew up in a generation and a culture where you didn't talk about 'unpleasant' things, you swept them under the carpet, you put on a brave face". ${ }^{42}$ This silence and avoidance of a traumatizing past can be understood as a coping method for survivors and a means of masking shame. The cultural attitude that negative affective responses ought to be concealed, and dealt with privately left survivors protective, isolated and silent, and their children on their own to try and comprehend the horrific unknown of their parents past.

Another manifestation of survivor shame has been the engraining of a 'false pride' in children by their parents, which Felix De Mendelsohn has noted in the families of Jewish survivors. ${ }^{43}$ This false pride works as a blanket defense from shame; it is "an aggrandizement of the self for defensive purposes" ${ }^{\prime 4}$, and a means of denying and counteracting shame. Arguably, this intense

\footnotetext{
${ }^{34}$ Ibid, 393.

35 Ibid, 395.

${ }^{36}$ Ibid, 394.

${ }^{37}$ Arlene Stein, "Feminism, Therapeutic Culture, And The Holocaust In The United States: The Second-Generation Phenomenon," Jewish Social Studies 16.1 (2009): 36.

${ }^{38}$ Marianne Hirsch, “The Generation of Postmemory," Poetics Today 29.1 (n.d.): 112.

${ }^{39}$ Ibid, 112.

${ }^{40}$ Stein, "Feminism, Therapeutic Culture, And The Holocaust In The United States: The Second-Generation

Phenomenon," 45.

${ }^{41}$ Ibid, 32.

42 Ibid, 37.

${ }^{43}$ De Mendelssohn, "Transgenerational Transmission of Trauma: Guilt, Shame, And The "Heroic Dilemma” 396.

${ }^{44}$ Ibid, 393.
} 
indoctrination of pride has operated alongside silence. By reclaiming an identity that was persecuted and stigmatized during the Holocaust through a performance of pride, Jewish individuals have presented an assuring illusion to others, a presentation of pure resilience and strength, healed wounds, and a reassurance that "things are O.K.". ${ }^{45}$ While indeed there has been much healing and resilience in the lives of survivors, this indoctrinated culture of pride has worked to silence and invisibilize children's "feelings of instability, of split or diffuse identity, [and] the painful legacy of their families' traumatization". ${ }^{46}$ Furthermore, because of this intense pride, parents have often became over-protective and over-bearing on their childrens' lives, imposing the expectation that they are responsible for redeeming their parent's loses and pain by becoming "nachas machines" 47 , a Yiddish term for pride from one's children. The success of their children became a means for parents to remedy the shame they carried for the suffering perpetrated against them. But, children found that "no matter how well they did and how much they wished to make their parents proud of them, it was never enough, they could never redeem their parents' pain". ${ }^{48}$ For some children, this invasive pride led them to reject their parents, their Jewish identity and their difference. Through their parents' pride these children experienced their own trauma, and some have displayed the physical symptoms of their emotional wounds: reoccurring nightmares, and stress-based rashes and tics, signs of the collateral damage caused by the unspoken shame of the Holocaust.

The aforementioned examples illustrate how shame and trauma consciously and unconsciously persist in Holocaust postmemory, and have shaped the lives of the children of survivors, despite the fact that they have no personal memories of these events. The afterlife of traumatic knowledge and experiences has been absorbed and internalized by the second-generation. As the son of one survivor has acknowledged: "somehow I've taken on a survivor's identity and feel so much like it all happened to me that I must feel the sorrow and take it away from my parents. I feel that my life is an assignment, a mission to make up for my parents' loses and give meaning to their survival". ${ }^{49}$ Similarly, a daughter of a survivor has recalled imagining that she had been in Auschwitz, and fantasizing about her pre-war experience. ${ }^{50}$ This blurring of the boundary between the self and parent through her over-identifying with her mother's traumatic past is clear evidence of the unconscious transmission of trauma so powerfully that children felt that they were living out their parent's experiences in their own lives. Arguably, this stems from the emotional potency of their parents lived experiences, and children's desire to contribute to healing their parents' pain.

The individual experiences of survivor's children created a platform for the emergence of a collective 'second-generation' identity during the 1970 's. ${ }^{51}$ During this time, children of survivors came together to share their silent pain through a public recognition of the emotional trauma they had encountered growing up with survivors. By taking up a collective identity and

\footnotetext{
${ }^{45}$ Ibid, 397.

${ }^{46}$ Ibid, 397.

${ }^{47}$ Stein, "Feminism, Therapeutic Culture, And The Holocaust In The United States: The Second-Generation Phenomenon," 41.

${ }^{48}$ Stein, "Feminism, Therapeutic Culture, And The Holocaust In The United States: The Second-Generation Phenomenon," 41.

${ }^{49}$ Ibid, 42 .

${ }^{50}$ Ibid, 42 .

${ }^{51}$ Stein, "Feminism, Therapeutic Culture, And The Holocaust In The United States: The Second-Generation Phenomenon," 30.
} 
using the feminist practice of consciousness-raising, they used their voices and experiences to break the culture of silence and shame surrounding the trauma of the Holocaust. They encouraged other second-generation survivors to do the same, by breaking the silence surrounding their parents' trauma, loses, and secrecy. ${ }^{52}$ Indeed, they engaged with a great deal of 'unlearning' as well, "accepting that our feelings, good and bad, are valid and don't need to be suppressed or denied". ${ }^{53}$ For these second-generation survivors, shame became a site of valuable processing and solidarity. By breaking the silence around their families and emphasizing shared experiences of affective haunting, they worked to validate and politicize their individual and shared emotional experiences.

The second-generation movement crucially acknowledged traumatizing experiences in the memory of the Holocaust, and offered what I believe is a helpful framework for reconceptualizing how we understand shame in Holocaust memory. This movement provided recognition and validation of the personal narratives of the children of survivors as a valuable piece of Holocaust memory. Unhinging shame from its negative social connotations, and recognizing its power to create solidarity among first and second-generation survivors, creates the possibility for fostering a collective 'survivor' identity that utilizes shame as a springboard for individual and collective healing from the trauma of the Holocaust and its haunting afterlife. Shame is an undeniable shared aspect of human lives and bodies. Thus critically unwrapping it has powerful potential to help us understand our lives and actions, recognize and examine individual and collective wounds, and come to understand and bridge our sites of difference.

Certainly, the Holocaust ignited shame for both survivors and persecutors, as well as their children -but it also created a wider global feeling of the shame surrounding the human capacity for atrocity. As such, I believe that redefining survivor shame from a secretive affect experienced by a select group of people, to a reinforcement of it as a feeling experienced by a larger global community which has "seep[ed] into the imaginary of other cultures (and other geographical spaces)" ", we are able to recognize how affective reactions are able to memorialize atrocities in a way more expansive than historical archives. Through expansive affective genealogy of shame, we are able to see the continuity and transmission of shame in Holocaust postmemory, and can work to create an enriched understanding of the affective haunting of other human rights atrocities. The affective genealogy of shame of the Holocaust can act as a lens to help us better understand other moments of collective and individual shame; for instance, among those who survived Canadian residential schools, Japanese Americans' internment during World War II, and the Armenian genocide, and to help to provide insight and healing and help bring light and healing to the survivors of these historical low points.

\footnotetext{
52 Ibid, 29.

53 Ibid, 37.

${ }^{54}$ Pascale Bos, "Postionality and Postmemory in Scholarship on the Holocaust," Women in German Year Book 19 (2003): 58 .
} 


\section{Bibliography}

Ahmed, Sara. "Shame Before Others." In The Cultural Politics of Emotion. 101-120. New York : Routledge, 2004.

Ayalon, Liat. "Making Sense Of The Past - Perspectives On Resilience Among Holocaust Survivors." Journal Of Loss \& Trauma 12.3 (2007): 281-293.

Biddle, Jennifer. "Shame." Australian Feminist Studies 12.26 (1997): 227-239.

Bos, Pascale. "Postionality and Postmemory in Scholarship on the Holocaust." Women in German Year Book 19 (2003): 50-74.

De Mendelssohn, Felix. "Transgenerational Transmission Of Trauma: Guilt, Shame, And The 'Heroic Dilemma'." International Journal Of Group Psychotherapy 58.3 (2008): 389401.

Dror, Esther. "The Shame is Always There." Sexual Violence Against Jewish Women During the Holocaust (2010): 275-289

Hirsch, Marianne. “The Generation of Postmemory.” Poetics Today 29.1 (n.d.) 103-126.

Leys, Ruth. From Guilt to Shame: Auschwitz and After. Princeton: Princeton University Press, 2007.

Maitles, Henry. "Surviving the Holocaust: The Anger and Guilt of Primo Levi." Journal of Genocide Research 4.2 (2002): 237-251.

Pytell, Timothy. "Shame and Beyond Shame.” New German Critique 117 (2012): 115-164.

Schneider, Gertrude. "Survival And Guilt Feelings Of Jewish Concentration Camp Victims." Jewish Social Studies 37.1 (1975): 74-83.

Stein, Arlene. "Feminism, Therapeutic Culture, And The Holocaust In The United States: The Second-Generation Phenomenon." Jewish Social Studies 16.1 (2009): 27-53. 